36 (1) | 2007

Miradas cruzadas sobre la influencia intelectual, cultural y científica entre Perú y Francia

\title{
Un capítulo de la influencia francesa en la medicina peruana: Ernesto Odriozola y la Enfermedad de
} Carrión

Un chapitre de l'influence française sur la médecine péruvienne. Ernesto

Odriozola et la Maladie de Carrión

One chapter of the French influence on Peruvian medicine. Ernesto Odriozola

and Carrion's Disease

\section{Marcos Cueto}

\section{(2) OpenEdition}

Journals

Edición electrónica

URL: http://journals.openedition.org/bifea/4561

DOI: $10.4000 /$ bifea.4561

ISSN: 2076-5827

\section{Editor}

Institut Français d'Études Andines

\section{Edición impresa}

Fecha de publicación: 8 mayo 2007

Paginación: 67-83

ISSN: 0303-7495

Referencia electrónica

Marcos Cueto, « Un capítulo de la influencia francesa en la medicina peruana: Ernesto Odriozola y la Enfermedad de Carrión », Bulletin de l'Institut français d'études andines [En línea], 36 (1) | 2007,

Publicado el 08 mayo 2007, consultado el 03 diciembre 2020. URL : http://journals.openedition.org/ bifea/4561 ; DOI : https://doi.org/10.4000/bifea.4561

Les contenus du Bulletin de l'Institut français d'études andines sont mis à disposition selon les termes de la licence Creative Commons Attribution - Pas d'Utilisation Commerciale - Pas de Modification 4.0 International. 


\title{
Un capítulo de la influencia francesa en la medicina peruana: Ernesto Odriozola y la Enfermedad de Carrión
}

\author{
Marcos Cueto*
}

\begin{abstract}
Resumen
Durante el cambio del siglo XIX al XX, la medicina clínica francesa y la geografía médica europea tuvieron una fuerte, y poco estudiada, influencia entre los médicos peruanos. Los objetivos de este artículo son analizar un evento importante de esta influencia y resaltar factores locales en la recepción de la misma, como el nacionalismo y la búsqueda de visibilidad académica internacional publicando trabajos en francés. Los médicos peruanos enfatizaron las características únicas del medio ambiente ligado a la salud y la enfermedad en los Andes, especialmente en relación con una enfermedad bacteriana conocida como la Enfermedad de Carrión (hoy mejor conocida como bartonellosis). El origen del nombre de la enfermedad puede rastrearse al sacrificio de un estudiante de medicina peruano de fines del siglo XIX que experimentó en su propio cuerpo los síntomas de una enfermedad popularmente conocida como la verruga peruana. Carrión murió en su intento y se convirtió en el símbolo de la emergente tradición de los médicos profesionales. Ernesto Odriozola, un compañero de clase de Carrión que siguió estudios graduados en Francia, publicó en París el primer estudio comprensivo de la historia, distribución geográfica y tratamiento de la enfermedad. Su libro se convirtió rápidamente en un hito de la medicina peruana y su autor llegó a ser un Decano en la Facultad de Medicina de la Universidad de San Marcos. Este libro proporciona algunas claves para entender la práctica de la medicina occidental en un país marcado por diferencias étnicas y culturales.
\end{abstract}

Palabras clave: historia de la medicina, Enfermedad de Carrión, verruga peruana, universidad de San Marcos

* Universidad Peruana Cayetano Heredia. Pude completar este trabajo gracias a la valiosa asistencia de Ellenore Hibon. E-mail: mcueto@upch.edu.pe 


\title{
Un chapitre de l'influence française sur la médecine péruvienne. Ernesto Odriozola et la Maladie de Carrión
}

\section{Résumé}

À la fin du XIXe siècle et au début du XXe la médecine clinique française et la géographie médicale européenne eurent une forte influence, bien que peu étudiée, sur les médecins péruviens. Le but de cet article est d'analyser un événement important qui a trait à cette influence et de mettre en avant, à ce sujet, des facteurs locaux, comme par exemple le nationalisme et la recherche de visibilité académique sur le plan international grâce à la publication de travaux en français. Les médecins péruviens mirent l'accent sur les caractéristiques uniques de l'environnement lié à la santé et à la maladie dans les Andes, et plus particulièrement une maladie bactérienne connue comme la Maladie de Carrión (plus connue aujourd'hui sous le nom de bartonellose). Le nom de la maladie trouve son origine dans le sacrifice, à la fin du XIXe siècle, d'un étudiant péruvien en médecine qui expérimenta sur son propre corps les symptômes d'une maladie plus connue sous le nom de verrue péruvienne, pour voir quels en seraient les effets. Carrión mourut au cours de l'expérience et devint le symbole de la toute nouvelle tradition des médecins professionnels. Ernesto Odriozola, condisciple de Carrión, qui fit ses études supérieures en France, publia à Paris une première étude permettant de comprendre I'histoire, la distribution géographique et le traitement de la maladie. Son livre devint rapidement une référence de la médecine péruvienne et son auteur devint doyent de la Faculté de Médecine de I'université de San Marcos. Ce livre fournit quelques clés pour comprendre la pratique de la médecine occidentale dans un pays marqué par les différences ethniques et culturelles.

Mots clés : histoire de la médecine, Maladie de Carrión, verrue péruvienne, université de San Marcos

\section{One chapter of the French influence on Peruvian medicine. Ernesto Odriozola and Carrion's Disease}

\begin{abstract}
During the turn of the 20th century, French clinical medicine and European medical geography had a strong, and little studied, influence among Peruvian physicians. The goals of this paper are to analyze to an important instance of this influence and to highlight local developments influencing its reception, such as nationalism and the search for international academic visibility by publishing in French. Peruvian physicians emphasized the uniqueness of the health and disease environment of the Andes, especially with regards to a bacterial disease called Carrión's Disease (today better known as bartonellosis). The origin of the name of the disease can be traced to the sacrifice of a Peruvian medical student in the late nineteenth century who experimented in his own body the symptoms of a disease popularly known as Verruga Peruana. Carrión died in his attempt and rapidly became the symbol of the emerging tradition of professional medicine. Ernesto Odriozola, a classmate of Carrion who pursued graduate studies in France, published the first comprehensive study on the history, geographical distribution, and medical treatment of the disease in Paris. His book rapidly became a landmark in Peruvian medicine and its author Dean of the School of Medicine of the University of San Marcos. His work also provides some clues for understanding the practice of Western medicine in a society marked by ethnic and cultural differences.
\end{abstract}

Key words: history of the medicine, Carrion's Disease, Peruvian verruga, University of San Marcos

La medicina francesa ha tenido una importante influencia entre los doctores peruanos desde fines del siglo XVIII. Uno de los personajes más simbólicos de esta influencia fue José Casimiro Ulloa, quien a mediados del siglo XIX viajó a Francia para entrenarse en los métodos de la 
medicina de Hospital en París y que posteriormente fundó en Lima la revista Gaceta Médica de Lima. Este trabajo va a ocuparse de otro momento importante de la influencia francesa en la medicina peruana. Un momento cuando la educación y la investigación médica nacional estaban institucionalizándose y asociándose a una enfermedad nativa, y empezaban a tener líderes que eran conocidos internacionalmente.

Entre fines del XIX y comienzos del siglo XX las ideas y métodos de la medicina clínica francesa y de la geografía médica europea fueron adaptadas por doctores peruanos y latinoamericanos que vivían en países considerados como periféricos a los centros mundiales de la ciencia. Muchos de ellos viajaron para estudiar en la Facultad de Medicina de París y regresaron a sus países con nuevos conceptos, técnicas y perspectivas. Se conoce aún poco acerca de este proceso. Existen estudios sobre la difusión y recepción de las especialidades modernas y emblemáticas de ese período como la medicina tropical, la bacteriología y la Teoría del Germen de la Enfermedad en diversos contextos latinoamericanos de inicios del siglo XX (Cueto, 2004). Sin embargo, se ha producido poco sobre el complejo proceso de adaptación de influencias europeas en la clínica y en la práctica médica fuera del Viejo Continente. El objeto de este artículo es contribuir a la historia de la medicina peruana analizando este problema poco tratado (Peard, 1999; Beldarraín, 2000). Es decir los estudios históricos han enfatizado el examen de la dimensión investigativa, de laboratorio, y generalmente bacteriológica, que comúnmente ha estado asociada al nombre de grandes científicos franceses de fines del siglo XIX como Louis Pasteur; pero poca atención se ha prestado al trabajo clínico que era en el que eran entrenados la mayoría de estudiantes de medicina y era el que ejercían la mayoría de doctores en los hospitales y en la práctica privada.

Asimismo, examinaré la relación entre el incipiente desarrollo de un nacionalismo médico - funcional a la legitimación de una profesión emergente- y la adaptación de la clínica y la geografía médica europeas en una sociedad marcada por diferencias étnicas y culturales. Es necesario mencionar que tanto la clínica como la topografía y geografía médicas tuvieron un notable desarrollo en Francia, y fueron uno de los aspectos que más llamaron la atención de los doctores peruanos. Finalmente, analizaré estas influencias entre los médicos provincianos.

Los médicos peruanos de inicios del siglo XX enfatizaron el carácter distintivo del entorno de la salud y la enfermedad en los Andes, especialmente con respecto a una enfermedad transmisible que empezaba a ser conocida como la Enfermedad de Carrión (hoy más conocida como bartonellosis, transmitida por el vector Lutzomia verrucarum y producida por la bartonella bacilliformis) (Maguiña, 1998; Herrer, 1990). La enfermedad se caracteriza por fiebres fulminantes, anemia y verrugas (o erupciones nodulares en la piel distintas a las producidas por otros males). El estudio local de la distribución geográfica de la enfermedad estaba entrelazado con un nuevo tema en la medicina tropical: la aclimatación humana en alturas elevadas así como la inmigración y la explotación comercial de los recursos naturales que existían en estas regiones. Arqueólogos, historiadores y médicos notaron la representación de verrugas típicas de la enfermedad en cerámicas precolombinas. Asimismo, existían estudios sobre la relación entre las dos manifestaciones clínicas del mal: fiebre aguda y la Verruga Peruana (Lastres, 1957; Chultz, 1968; Allison et al., 1974).

Desafortunadamente, no existe una cifra que indique el número de personas afectadas por la Enfermedad de Carrión a fines del siglo XIX. Los servicios de salud pública peruanos de la época eran primordialmente urbanos y la vigilancia epidemiológica estaba poco desarrollada. Sin embargo, a pesar de no ser una gran causa de mortalidad, la enfermedad tenía incidencia en la morbilidad de algunas regiones andinas. Según un informe de 1910 sobre Cajamarca, entre 5 y $20 \%$ de la población indígena era afectada por la enfermedad (Pérez Velásquez, 1914: 179). La cifra aparece mucho menor en el censo nacional de 1940 donde se preguntó sobre esta dolencia y resultó que solo 0,95 \% de la población nacional (5 887 individuos) sufría de verruga. La enfermedad se concentraba en algunos departamentos andinos como Ancash, donde ocurrían la mayoría de casos (3 786 casos) y la sierra del departamento de Lima (con 
1077 casos); pero se sospechaba a fines del siglo diecinueve que podría existir en otras regiones andinas (Perú, Ministerio de Hacienda y Comercio, 1940, vol. 1: 470-471).

El nombre de la enfermedad derivaba del estudiante de medicina peruano Daniel A. Carrión, que se inoculó en agosto de 1885 la sangre de un enfermo de verrugas para estudiar en su propio cuerpo y registrar los síntomas que predecían al mal, pero que murió en octubre de ese mismo año. Hoy en día es considerado como un mártir de la medicina peruana y el día de su muerte (el 5 de octubre) es considerado el día de la medicina peruana (Paz Soldán, 1927; Frisancho Pineda, 1986; Delgado Matallana, 2001). Un estudio reciente ha analizado el proceso de la construcción cultural de Carrión como héroe médico (Murillo et al., 2002). En un trabajo anterior, el autor de este texto examinó la competencia entre bacteriólogos de Lima y la Universidad de Harvard que a comienzos del siglo veinte compitieron para determinar la etiología de la enfermedad (Cueto, 1996). En este artículo trataré acerca de los clínicos que ejercían la medicina en Lima y en áreas golpeadas por la enfermedad.

\section{UN PERUANO EN PARÍS}

El personaje principal de este trabajo es el médico peruano Ernesto Odriozola (1862-1921), proveniente de una familia de aristócratas, políticos e intelectuales. Fue el nieto de un importante historiador peruano e hijo de Manuel Odriozola, Decano de la Universidad Nacional Mayor de San Marcos y fundador de la Academia Nacional de Medicina (creada en 1884). Uno de los mayores logros académicos de Ernesto Odriozola fue el libro La Maladie de Carrion; ou, la verruga péruvienne, publicado en París (Odriozola, 1898; 1946)1. Según historiadores de la medicina peruana de la primera mitad del siglo veinte, esta obra creó la base para una medicina «nacional» (Valdizán, 1922). Este artículo está basado en el libro de Odriozola, trabajos biográficos, así como los artículos de Odriozola, folletos y otras pocas publicaciones antiguas conservadas en la Biblioteca Nacional de Lima y en algunas bibliotecas de Francia como la Biblioteca Nacional de París (Valdizán, 1920; 1922; 1959; Belmont Parker, 1919)2.

Ernesto Odriozola estudió los primeros años de medicina en la Universidad de San Marcos (teniendo como compañero de aula a Carrión). Debido al exilio político de su padre hacia el final de la Guerra del Pacífico, viajó a Europa a terminar sus estudios en París. Entonces la Facultad de Medicina de esa ciudad experimentaba un proceso de crecimiento de alumnos y de su prestigio internacional y contaba con renombrados profesores como Jean-Martin Charcot en la cátedra de la clínica de enfermedades nerviosas quien revolucionó la enseñanza de la neurología y la psicología. Odriozola llegó a París cuando esta ciudad estaba convirtiéndose en el centro de una nueva etapa de gran prestigio cultural y artístico de Francia; una etapa conocida como la Belle Époque, signada por la paz entre las potencias europeas, marcada por la aparición de innovaciones tecnológicas aplicadas rápidamente a la industria, caracterizada por una mejora del nivel de vida de los franceses, y que duraría hasta iniciada la primera Guerra mundial en 1914 (Willms, 1997; De Areilza, 1989).

Fuera - y paralelamente a- de la Universidad Ernesto Odriozola trabajó bajo la tutela de Maurice Lettulle, un renombrado médico del Hospital Tenon (y a partir de 1889 encargado - y luego profesor - de anatomía patológica en la Facultad de Medicina de París). Como era la costumbre para los estudiantes de medicina franceses de la época el trabajo teórico y en clases se complementaba con la experiencia práctica que se adquiría en hospitales que no eran directamente controlados por la Facultad de Medicina. Odriozola ganó experiencia clínica en el prestigioso Hospital donde trabajaba Letulle. Era un gran establecimiento médico con más de

1 Una traducción en castellano publicada muchos años después: Odriozola (1946).

2 Desafortunadamente Odriozola no dejó documentación profesional o personal. 
600 camas, tres pisos, ubicado al noreste de la capital francesa e inaugurado en 1878 (ValleryRadot, 1948). Entonces, Letulle estaba interesado en una serie de temas médicos como las enfermedades cardíacas, de la que había hecho su tesis en 1879 y la tuberculosis. Un indicador de su ascenso profesional es que llegó a ser miembro del comité editorial de la prestigiosa revista La Presse Médicale. Una descripción biográfica del maestro francés resalta algunas de las características clínicas que seguramente transmitió al discípulo peruano:

«Bon clinicien, ardent éducateur des jeunes, qu'il initiait simultanément, suivant la tradition de Laennec [el inventor del estetoscopio], à l'observation du malade et à la pratique des autopsies». (Huguet, 1991: 297-299)3

Odriozola no era el único estudiante del Perú en haber escogido París para sus estudios. Desde mediados del siglo XIX hasta inicios del siguiente, esta ciudad era la meca para los estudiantes de medicina peruanos y latinoamericanos y el dominio del francés era para ellos casi una obligación. Distintas evidencias señalan que a comienzos del siglo XX se recibían las principales revistas médicas y científicas francesas, como por ejemplo la Revue de Pathologie Exotique (que eventualmente incluía trabajos de peruanos) y varios estudiantes peruanos fueron a estudiar a París — en la Facultad de Medicina o en el Instituto Pasteur-y luego regresaron al Perú a ocupar lugares destacados en la Universidad. La influencia francesa en la formación médica de San Marcos de comienzos del siglo XX fue recordada por un profesor de la Facultad de Medicina de Lima en los siguientes términos:

«La influencia de la escuela francesa en nuestra educación médica ha sido pues absoluta. Los nombres de los grandes maestros de aquella escuela son familiares para los médicos y los estudiantes peruanos, las obras francesas sirven de consulta a los catedráticos y los textos de esa misma nacionalidad son casi los únicos que los alumnos estudian». (Matto, 1908: 35)

Es también interesante recordar que cuando empezaba la segunda década del siglo XX se formó una asociación de médicos que reunían a doctores franceses, españoles y latinoamericanos y el primer país latinoamericano en adherirse fue el Perú gracias a otro médico peruano entrenado en París, Edmundo Escome4.

Además de seguir los pasos de su mentor Letulle en París, Ernesto Odriozola exploró novedosas perspectivas como la hipnosis, y fue alumno en clases de nuevas disciplinas como la de «enfermedades venéreas» que hasta entonces eran consideradas como un problema moral y no médico. También es importante destacar que se graduó de médico cumpliendo con todos los requisitos que pedía la Facultad de Medicina de París. El hecho que se graduara, completando los cursos y la tesis, fue un logro importante porque otros estudiantes peruanos llevaban cursos en París pero no concluían sus estudios. Odriozola se graduó en 1887 con una tesis sobre el corazón senil de más de 240 páginas y con elementos nuevos para una tesis como ilustraciones y 18 páginas de bibliografía. La dedicá a «mon cher maître docteur Letulle » y reconoció que fue él quien le inspiro el tema de su trabajo (Odriozola, 1988)5.

Pocos años después de haber presentado su tesis, y ya estando en Lima, Odriozola recibió copias de La Maladie de Carrion, un libro publicado en París por Carré et Naud. Este era un logro notable para un joven médico peruano. Al parecer había trabajado en el libro por algunos años desde sus estudios en París, completando el texto y los mapas en el Perú. Una reseña positiva publicada en una revista peruana indica que el libro de Odriozola inauguró su reputación local (La crónica

3 Sobre Letulle, ver Letulle (1955).

4 Esta asociación era la Union Médicale Franco Ibéro Américaine Umfia, y el dato es de «L’Umfia médicale Franco Ibéro Américaine ou UMFIA au P. Escomel au grand savant péruvien, 1927» (Dartigues, 1927) donde se dice «On peut dire que, gràce à Escomel, le Pérou fut la première des nations sud-américaines qui adhéra à notre projet et participa à sa réalisation [en 1912]».

5 Como lo hacían muchos estudiantes la publicó después como un libro (1888). Posteriormente publicó su tesis por partes en una revista de Lima (1889). 
Médica, 1898: 316). Pocos años después de su regreso de París, la asociación estudiantil médica peruana le otorgó un premio por esta publicación (Valdizán, 1922: 35).

¿Por qué publicó Odriozola su libro sobre Carrión en París? Existía en Francia —y en Europacierto interés en el tema; algo que está sugerido por una noticia en un prestigioso Diccionario Enciclopédico de Ciencias Medicas publicado en París en el siglo XIX, de la mención de la enfermedad en el importante libro de geografía médica del alemán Hirsh, y de una tesis de medicina en la Facultad de París escrita por Paul Dounon en 1871 (D'Ornellas, 1889: 34-35; Dounon, 18716). Es plausible pensar que Odriozola conociera estos trabajos.

Asimismo, fue probablemente alentado y asistido por su mentor francés Maurice Letulle, quien había publicado un año antes el libro Anatomie Pathologique en la misma editorial (Letulle, 1897). Letulle contribuyó con una breve sección sobre estudios bacteriológicos —sin hallazgos significativos - en el libro de Verruga de Odriozola y mantuvo a lo largo de los años un interés en el tema como lo indica una de sus publicaciones de 1910 donde discute si un enfermo que se encontró en Madagascar sufriría de la Maladie de Carrion. En ese trabajo coincidió con la convicción de los médicos peruanos sobre Carrión: «un jeune médecin péruvien, qui mourut victime de la science» y apoyándose en el texto de Odriozola, Letulle descartó que el caso sea de verruga y definió a esta enfermedad como una dolencia limitada a ciertos valles andinos (Letulle, 1910). El interés por la verruga se iba a mantener en Francia en años posteriores como lo sugieren una tesis de medicina y el capítulo de un importante texto de medicina coeditado por el decano de la Facultad de Medicina de París (donde se vuelva a citar el libro de Odriozola) (Guiart, 1925: 402)7.

Otro factor para publicar en francés fue la búsqueda del prestigio profesional. Aunque no hay evidencia exacta, es plausible asumir que como en el caso de otros intelectuales peruanos, Odriozola sentía que publicar en el extranjero y en francés era un logro formidable y una forma de recibir reconocimiento local. El hecho que fuese el primer libro publicado en francés por un doctor peruano aumentó su prestigio en el país. Odriozola y su libro tuvieron una fuerte influencia en el Perú por dos motivos: en primer lugar, la medicina peruana y la educación superior estaban marcadas, al menos hasta mediados del siglo veinte, por su admiración hacia la ciencia y cultura francesas, en segundo lugar, el libro trataba acerca de una enfermedad que se convirtió en el centro de una tradición médica emergente. Esta tradición desarrollada en torno a la Enfermedad de Carrión enfatizaba no solo las características especiales del país sino también la capacidad de los peruanos de producir conocimientos creativos y útiles.

En Lima, Odriozola siguió una brillante carrera universitaria. Fue nombrado profesor en la Facultad de Medicina de la Universidad de San Marcos; primero de Anatomía Topográfica y Medicina Operatoria, por concurso en 1890 (que se enseñaba en el sexto de los siete años de estudio en medicina) y en 1908 profesor de Clínica Médica (Valdizán, 1911: 320-321). Esta última era una de las cátedras más prestigiosas de la Facultad de Medicina y en la cual permanecería durante el resto de su carrera. Gracias a su talento y capacidad, así como a la procedencia de su familia y su formación francesa, se convirtió en uno de los médicos limeños más requeridos. Según un diccionario biográfico de la época era el médico obligado de consulta para «todos los casos difíciles» (Paz Soldán, 1917: 172). En 1907 llegó a ser subdecano de la Facultad y cuatros años después fue nombrado Decano de Medicina. Llegó a ser reelegido en ese cargo, ocupando el decanato por un total de doce años (1911-1921). Posteriormente llegó a ser vicerrector de la Universidad de San Marcos y miembro de la Sociedad de Beneficencia de Lima. Mientras fue Decano, creo nuevas cátedras como las de Sífilis, Neurología, Psiquiatría, Medicina Tropical y Cirugía Infantil (algunas de las cuales había visto formar parte de la enseñanza médica

6 No hemos podido ubicar esta obra pero está citada en p. 4. Table des Thèses soutenues a la Faculté de Medicine de Paris en 1871, 1872 Paris: A. Parent, Imprimeur de la Faculté de Médicine. Biblioteca de la Academia National de Medicina, París.

7 Asimismo otra tesis citada en el mismo año del libro, pero que suponemos fue posterior a la obra de Odriozola porque utiliza el término «maladie de Carrion», es la de Marc-Pusségur (1898). 
durante su estadía en Francia). Asimismo, sobrevivió la gran huelga estudiantil de 1919 en la cual aparecieron en la escena política nacional personajes que después serían famosos como Víctor Raúl Haya de la Torre y Raúl Porras Barrenechea. A pesar que no volvió a publicar ningún libro, escribió varios artículos y folletos, en los cuales retornó a algunas de las ideas presentadas en su libro seminal.

\section{EL PERÚ DE ODRIOZOLA}

La sociedad en la cual Odriozola enseñaría y ejercería la medicina experimentaba una mezcla de recuperación, tradición y modernización. El Perú, y sobretodo la ciudad de Lima, de finales del siglo XIX despertaba de su derrota en la Guerra del Pacífico e iniciaba un proceso de reconstrucción económica, educativa y política. Ello implicaba la organización de una economía de exportación y cierta estabilidad política creada por los regímenes militares que gobernaron el país hasta 1895. Después de ese año, cuando se inició la República Aristocrática, la estabilidad se incrementó con el liderazgo de una oligarquía, una elite civil europeizada basada en Lima, que basaba su riqueza en las grandes haciendas, el comercio y la economía de exportación (Flores Galindo \& Burga, 1980). Esta elite promovió la reorganización de instituciones académicas como la Facultad de Medicina de San Marcos, la única de su tipo en el país y que recibió en 1903 nuevas y magníficas instalaciones en la avenida Grau cerca del Hospital Dos de Mayo donde se realizaban la mayoría de las lecciones médicas.

La modernización que experimentaron tanto la ciudad como la educación superior y la vida intelectual, trataron de seguir patrones franceses como lo sugiere la contratación de profesores franceses en San Marcos, y otros centros de enseñaza superior de Lima, y la influencia del positivismo entre los profesores universitarios. Por ejemplo, poco antes de acabar el siglo XIX, la Facultad de Letras creó la Cátedra de Sociología, una disciplina que según el francés Augusto Comte, el fundador del Positivismo, coronaba la jerarquía de las ciencias. Según un estudiante de la época, el Positivismo era como un «sarampión» entre los catedráticos (Castro Oyanguren, 1920: 131)8.

Los estudios de Odriozola, así como las expediciones al interior, las exploraciones científicas mineras y los inventarios de flora y fauna, fueron considerados funcionales para los gobiernos de inicios del siglo XX que tenían interés en usar los recursos naturales nacionales para la creciente economía de exportación. La aplicación de la ciencia y la medicina era considerada esencial en la protección y el incremento de la productividad de la economía. Los gobiernos y las elites limeñas también consideraban que la asesoría médica sobre las características de los Andes - con una adecuada legislación - podía tener un impacto positivo en la promoción de la codiciada inmigración europea. Además, el tener como profesor universitario al autor de un libro en francés incrementaba el prestigio de instituciones académicas nacionales.

Estos sucesos ocurrieron en un país donde existían brechas culturales, generadas en parte por diferencias y dominaciones de origen étnico, entre la elite de Lima y el resto del país, así como entre los médicos de Lima y la mayoría de los pacientes de los hospitales. De acuerdo a dos nociones — que venían del período colonial pero que se ampliarían durante el siglo veinte - el país estaba organizado en tres regiones «naturales» y había una estrecha relación entre etnicidad y topografía. La costa, que representaba el $13 \%$ del territorio $\left(180000 \mathrm{~km}^{2}\right)$ era donde existían haciendas modernas, casas comerciales, bancos e industrias. Los Andes estaban marcados por un sistema agrícola poco desarrollado y constituían el $32 \%$ del territorio; mientras que la Amazonía, habitada por tribus «no civilizadas» representaba el $55 \%\left(700000 \mathrm{~km}^{2}\right)$ pero estaba apenas poblada y tenía una economía considerada atrasada (Rebagliati, 1940). Según un cálculo de comienzos de la década de 1920 (no hubo censo nacional entre 1875 y 1940), solo 11 \% de

8 Sobre el Positivismo, véase Salazar Bondy (1965). 
los 3382525 peruanos eran blancos y vivían principalmente en los centros urbanos y costeros. El resto de la población del país era indígena y rural, con la excepción de los 60000 chinos y 70000 personas de origen africano (Striglich, 1922: 2).

El contraste entre costa y sierra simbolizaba para algunos la oposición entre modernidad y tradición. La cultura, la ciencia, la medicina occidental, la educación superior, los inmigrantes europeos y el poder político se concentraban especialmente en Lima. La mayoría de la población que vivía en los Andes era indígena, hablaba quechua, se apoyaba en la medicina tradicional y se resistía a una integración total a la economía nacional de exportación. En contraste, los médicos peruanos eran frecuentemente de Lima y hablaban sólo castellano; asimismo tenían usualmente una percepción negativa de la cultura indígena y de la medicina tradicional a la que consideraban «primitiva». Al mismo tiempo se respaldaban en la ciencia europea para proclamar la superioridad de sus cuidados de la salud y la necesidad del Estado de controlar a los charlatanes, los productores de remedios «mágicos» para las enfermedades, los herbolarios chinos, y los curanderos indígenas.

\section{UN LIBRO PERUANO EN FRANCÉS}

El libro La Maladie de Carrion de Odriozola fue el primer estudio completo (según los estándares de su época) sobre la enfermedad de Carrión. Incluía información acerca de la historia, el clima, la vegetación, los lugares y las personas involucradas en este mal. La obra resumía los datos médicos e históricos disponibles respecto a la distribución geográfica, el diagnóstico y la patología de la enfermedad, en una elegante edición de 217 páginas ilustradas con cuatro mapas y varias fotografías. Es importante mencionar que el autor obtuvo la mejor ayuda local disponible para la producción de los mapas. Una de las instituciones científicas limeñas principales de entonces fue la Sociedad Geográfica de Lima (creada por el Estado en 1888) que elaboró los mapas que utilizo Odriozola en su obra.

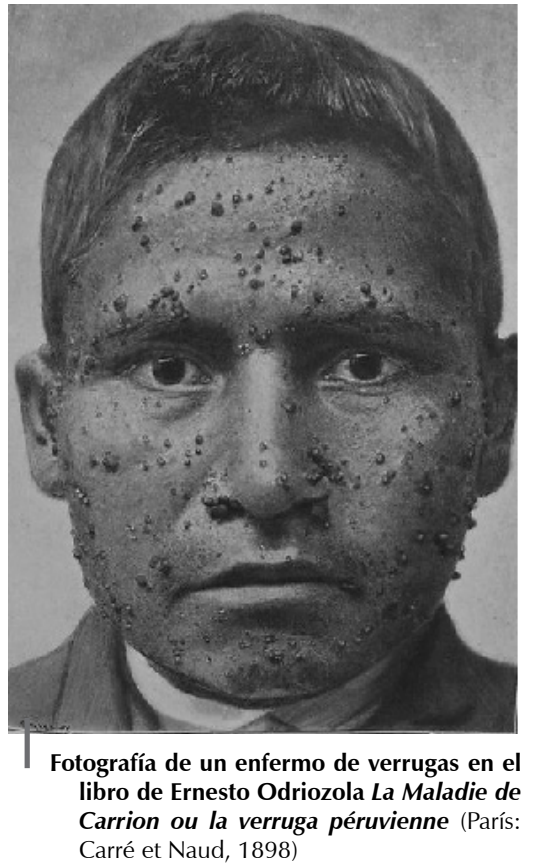

Es también interesante mencionar que Odriozola utilizó un mapa nacional en el cual los límites del Perú estaban magnificados, al incluir territorios en disputa como las «provincias cautivas» de Tacna y Arica, que en realidad estaban en poder de Chile desde el final de la Guerra del Pacífico. Al hacer de esta manera los mapas se seguía una costumbre de los gobiernos peruanos de fines del siglo XIX y comienzos del XX que los usaban para resaltar sus demandas y demostrar su patriotismo. Una imagen agrandada del Perú era instrumental en un período de tensa negociación diplomática con Chile, y en una época en la que muchos peruanos creían que el país debía recuperar las provincias perdidas en la Guerra. Asimismo, era una alusión indirecta a un problema parecido que había tenido Francia (con Alsacia y Lorena) al final de la Guerra Franco Prusiana (1870-1871); una demanda francesa que solo se resolvió al final de la Primera Guerra Mundial.

El libro de Odriozola estaba organizado en cuatro capítulos: la historia de la enfermedad, su distribución geográfica, un estudio de la fase de fiebre y un análisis posterior de las erupciones de verruga de la Enfermedad de Carrión. En el primer capítulo, el autor se remitió a las crónicas coloniales españolas e informes del siglo XIX hechos por médicos, naturalistas y viajeros. Estas fuentes indicaban que el primer encuentro entre la enfermedad y los conquistadores ocurrió a inicios del siglo XVI en Coaque (hoy Ecuador). Existía menos información para el resto del período colonial. Odriozola sugería que esta ausencia era el resultado 
de una guerra microbiológica; el «germen» de Carrión se retiró a regiones aisladas de los Andes cuando nuevos y más poderosos microorganismos como el de la viruela y el sarampión devastaron a la población indígena al comienzo de la colonización española. El primer capítulo de La Maladie de Carrion también menciona que en el siglo XIX se atribuía el mal al agua de manantiales de algunas regiones de los Andes. Evitar estos manantiales era una de las formas más comunes de prevención.

El primer capítulo del libro de Odriozola también analizaba un importante brote de fiebre ocurrido a fines de 1870 en las mismas regiones donde la verruga era endémica. La epidemia se convirtió en un notorio problema debido a la alta mortalidad entre los trabajadores del ferrocarril que intentaba unir Lima y la Sierra Central y fue llamada la Fiebre de Oroya (porque Oroya era el destino final de la línea férrea). Algunos creían que la verruga y la Fiebre de Oroya eran dos entidades clínicas diferentes, sin embargo, la mayoría de médicos apoyaban la idea que la epidemia de la Oroya era la primera fase de la verruga. Incluso la experiencia trágica de Carrión parecía confirmar esta concepción (trató de describir los síntomas que precedían la erupción de verrugas pero murió con fiebres altas y anemia).

Sin embargo, fue recién con el libro de Odriozola que apareció un informe clínico claro y completo de las dos fases de la enfermedad. Odriozola recurrió a conocimientos topográficos y al diagnostico clínico para demostrar que lo que llamada «Fiebre de Oroya» existía solo en los lugares en los cuales estaba presente la verruga y que la experiencia médica demostraba que los sobrevivientes de la fiebre experimentaban verrugas con distintos grados de intensidad. La Maladie de Carrion fue considerada en los años siguientes por muchos médicos peruanos como el libro de texto que respalda sus convicciones y la demostración que las dos enfermedades eran realmente una. Asimismo, era una prueba escrita que definía por qué Carrión era un autentico mártir. Sin embargo, como inicialmente no había pruebas bacteriológicas, algunos investigadores extranjeros, especialmente norteamericanos como Richard Strong de la Universidad de Harvard, cuestionaron la validez del experimento de Carrión y la noción que era en realidad una sola enfermedad con dos fases como creían los peruanos (Cueto, 1996).

En el segundo capítulo de su libro, Odriozola estudió la distribución geográfica de la enfermedad, la que consideraba exclusiva a algunos departamentos andinos. Resaltó la presencia de la dolencia en Ancash que, luego de Lima, era el departamento más poblado de Perú (343 660 habitantes), y que tenía ricos recursos mineros y agrícolas inexplotados (Striglich, 1922). Odriozola también enfatizó la presencia de la Enfermedad de Carrión en medio ambientes únicos donde se combinaba un clima tropical y alturas elevadas, como las quebradas de los valles interandinos ubicadas entre 700 y 1000 metros sobre el nivel del mar, marcados por la mucha humedad y las altas temperaturas. A pesar que estos valles estaban situados relativamente cerca de la costa, a aproximadamente 60 kilómetros de distancia, estaban cerca de las altas y frías montañas de los Andes por lo cual tenían un clima mucho más cambiante y diferente del litoral.

Según Odriozola, la enfermedad se agudizaba solo en ciertas quebradas ubicadas en posición paralela a la costa del Pacífico ya que según él no recibían vientos. Esta opinión se combinaba con otras ideas miasmáticas como la falta de ventilación de estos lugares (según las teorías médicas miasmáticas la falta de ventilación y el calor, la descomposición de las materias orgánicas y, por tanto, la enfermedad). Él creía que la combinación única de una altura moderada, una temperatura cambiante pero generalmente elevada y la poca circulación del aire explicaba por qué la enfermedad existía solo en los Andes. Odriozola no le prestó demasiada atención a la etiología de la enfermedad o su modo de transmisión como hubiesen hecho los partidarios de la bacteriología; creía tan solo que esta no era contagiosa. También mencionó vagamente que su origen se podía deber a un «virus» de los manantiales de los Andes (era una vieja creencia de inspiración miasmática que la enfermedad provenía del agua) y como muchos otros médicos de su época, creía que, como en el caso de la malaria, la remoción de tierra para la construcción de carreteras producía brotes epidémicos.

En el análisis más clínico de La Maladie de Carrion —los capítulos tercero y cuarto- Odriozola hizo un esfuerzo especial para diferenciar la enfermedad de otras infecciones tropicales, 
principalmente la malaria (a pesar que consideraba la quinina —el remedio típico contra la malaria - como beneficiosa para los enfermos con la Enfermedad de Carrión). Más tarde, distinguió la enfermedad de otras enfermedades como la Frambesia que existían principalmente en el Amazonas (Odriozola, 1903). Según Odriozola, esta enfermedad única solo existía en la vertiente occidental de los Andes peruanos (esta noción sería descartada a mediados del siglo veinte). Consecuentemente, la enfermedad era para Odriozola una especie de frontera entre dos regiones del Perú: la Costa y la Sierra. Esta noción apoyaba el principio organizativo del territorio peruano y su relación con la etnicidad, mencionados anteriormente. Odriozola y varios médicos y geógrafos peruanos de la época, reforzarían las percepciones de las tres regiones del Perú: la Costa, la Sierra y la Amazonía, y que cada una estaba poblada por un grupo étnico diferente. Odriozola sugería también que cada grupo se había adaptado a su medio ambiente y que cada región experimentaba un perfil epidemiológico distingo de enfermedad endémicas y epidémicas.

Si bien el libro de Odriozola no ofreció mayores detalles sobre los patrones regionales de las enfermedades, sus ideas tuvieron una influencia en la práctica y la educación médicas. Una de sus metas era animar a los estudiantes y doctores peruanos a que desarrollaran una capacidad específica: el interrogar cuidadosamente a sus pacientes indígenas. Este interrogatorio serviría para averiguar sus lugares de origen y los sitios visitados previamente a la consulta; en el caso de un paciente que sufriera de fiebre aguda, esta información podría ser usada para identificar posibles casos de la Enfermedad de Carrión en sus etapas iniciales; cuando la recuperación era más probable. Algunos años después de la publicación de su libro, Odriozola explicó a sus alumnos:

«Entre nosotros la investigación de los lugares donde el paciente ha estado tiene una importancia crucial».

Incluso consideró que esta información, en la mayoría de los casos, era suficiente para un diagnóstico adecuado (Odriozola, 1904: 49)9. Años después, otro médico peruano subrayaría la interrogación a los pacientes como una forma de encontrar nuevas zonas de origen de la enfermedad (Maldonado, 1933). Para otro médico más ambicioso, esta información permitiría la erradicación de la enfermedad del mundo ya que esta solo existía en los Andes peruanos (Arce, 1922: 68).

Según Odriozola la interrogación a los pacientes era una tarea difícil en el Perú que había que aprender debido a las diferencias culturales entre los prestadores de salud y la mayoría de sus pacientes. En una de sus clases explicó que esta dificultad existía porque:

«el número más grande de nuestros pacientes está conformado por indios y chinos». (Odriozola, 1904: 4)

Para el médico peruano no solo era una diferencia lingüística. También se trataba de una diferencia en las concepciones de la salud, la enfermedad, y la actitud ante la vida. En un texto caracterizaba a la población india de «apática»e indolente al negarle ayuda a los médicos, llegando incluso a ser hostil hacia los doctores (Odriozola, 1904: 212). En consecuencia, según Odriozola una interpelación cuidadosa del paciente era un medio que, combinado con el conocimiento proporcionado por la geografía médica, podía asegurar una intervención clínica precisa.

Para Odriozola, la falta de un tratamiento efectivo (las medicinas principales de finales del siglo XIX eran la quinina y tónicos que aliviaban la fiebre y las erupciones) daba más importancia al conocimiento topográfico y clínico para la prevención de la enfermedad (apoyaría esta idea en su libro y en artículos subsiguientes). Odriozola se dio cuenta que la mayoría de los pobladores andinos que vivían en zonas donde la enfermedad era endémica usualmente experimentaban los efectos leves de la Enfermedad de Carrión durante su niñez y luego adquirían inmunidad. Una información detallada acerca de los centros endémicos de la enfermedad podía ser útil

9 De 1904 a 1913, las conferencias de Odriozola se publicaron en la Gaceta de los Hospitales y de 1914 a 1921 en La Crónica Médica. Algunas de las conferencias de 1904 fueron recopiladas en el libro Lecciones clínicas. Se conservan todas en la Biblioteca Nacional del Perú. Referente a sus publicaciones, ver también La Crónica Médica (1921: 127). 
para advertir a los viajeros y extranjeros que visitaban, trabajaban o colonizaban estas regiones. Usando un término poco definido, Odriozola dijo incluso que era posible «aclimatar» a los extranjeros que pretendían vivir y trabajar en los Andes. En algunas fotografías del libro de Odriozola se representaba la medicina tropical de la época retratando a indios con casos leves de la Enfermedad de Carrión y presentando en cambio a extranjeros con ataques severos de verruga. Las imágenes sugerían que el riesgo de adquirir manifestaciones agudas de la enfermedad era mucho mayor para los extranjeros que para los nativos (Odriozola, 1903: 8). La idea implícita era que cualquier intento de colonización de los Andes por limeños o europeos debía tener en consideración el consejo de la clínica médica.

El significado nacionalista de La Maladie de Carrion debe ser resaltado. Odriozola «nacionalizó» la Enfermedad de Carrión al otorgarle el nombre de un peruano y al atribuirle su ubicación especial en el Perú. Esta «nacionalización médica» sirvió para propósitos locales e internacionales; la insistencia de Odriozola en la existencia de la enfermedad únicamente en los Andes estaba dirigida en última instancia a realzar el país. Además, la idea de la existencia de una entidad clínica particular ciertamente despertó un interés científico internacional que ha durado hasta el día de hoy (Maguiña \& Gotuzzo, 2000). El epónimo de Carrión sugería que los médicos peruanos podían realizar contribuciones internacionales originales. El nacionalismo médico también tenía motivaciones sociales y políticas locales porque ayudaba a legitimar la profesión médica en un país en el cual la medicina occidental estaba solo parcialmente desarrollada en los centros urbanos. Odriozola presentaba a los médicos con formación universitaria (y no a curanderos, charlatanes u otros médicos tradicionales) como los mejores cuidadores de la salud y los mejores consejeros gubernamentales para las políticas poblacionales.

El nacionalismo médico tuvo también connotaciones étnicas y de clase. Según el análisis de Uriel García, en el libro de Odriozola y en otras publicaciones de fines del XIX, se utilizó un dibujo embellecido y «europeizado» de Carrión (quien en realidad era mestizo según las fotografías originales). Esto fue hecho como una forma de legitimar la auto-experimentación de Carrión entre las élites limeña y extranjeras. Parecía más fácil validar a un héroe médico local que se parecía al estereotipo étnico de un estudiante europeo (García-Cáceres \& García, 1991). En los años subsiguientes, se publicó en un periódico provincial otro dibujo alternativo de Carrión; una imagen que enfatizaba los rasgos faciales indígenas y mestizos originales del héroe médico peruano (Murillo et al., 2002).

En 1921, luego de dos décadas de enseñar y practicar la medicina en Lima, Odriozola se encontraba en la cima de su carrera; en ese año fue nombrado por tercera vez presidente de la prestigiosa Academia Nacional de Medicina, la institución creada por su padre. Había recibido honores y reconocimientos en el país y en el extranjero. Ese año fue también el último de su vida; una edición especial de la revista médica peruana de entonces se dedicó a recordarlo. Incluía una carta enviada por el editor del Journal des Praticiens de París que hacía eco del nacionalismo francés. La carta decía que los médicos franceses habían perdido:

«un amigo sincero que nunca dejó de pelear contra la influencia alemana en su país, por una propaganda constante para la ciencia francesa».

La cita aludía al otro modelo de medicina europea, es decir la alemana, que tuvo mayor influencia en América del norte que en la del Sur. (Asimismo, es importante recordar que entre las varias sociedades científicas a las que perteneció Odriozola estuvo la de Anatomía de París.) Otra carta del editor del prestigioso Paris Médical revelaba que la influencia francesa en el Perú no pasaba desapercibida en París. Según esta carta, la muerte de Odriozola significaba la pérdida de «un grand ami de la France»10.

10 Las citas son del Journal des Practiciens (1921) y el Paris Médical (1921). Aparecieron en La Crónica Médica (1921: 181). 


\section{LA CONTINUIDAD DE UNA TRADICIÓN}

Durante las primeras décadas del siglo veinte, jóvenes científicos peruanos recurrieron a la bacteriología y luego a la entomología para encontrar la causa y el modo de transmisión de la Enfermedad de Carrión. En 1909 y 1912, la bacteria y el mosquito relacionados a la enfermedad fueron hallados. Sin embargo, fue solo en los años veinte cuando estos descubrimientos fueron aceptados totalmente por las comunidades científicas del Perú y el exterior (Cueto, 1996). Durante el período en que se realizaba estos estudios Odriozola decía que no sentía mucha simpatía por la bacteriología (a pesar que era la disciplina de moda entre la elite médica de la época), para él la observación clínica era la cualidad esencial de un médico y el ápice de la medicina. En una de sus clases, le aconsejó a sus alumnos que:

«reaccionaran enérgicamente contra la influencia tiránica... de la bacteriología [que quería imponer] a una perspectiva unilateral».

También creía que la medicina clínica debía mantener «siempre bajo su control toda manipulación bacteriológica» (Odrizola, 1904: 4).

Los estudios de laboratorio sobre la Enfermedad de Carrión realizados a comienzos del siglo XX tomaron fuerza en la Facultad de Medicina de San Marcos. Por ello la visibilidad de los estudios clínicos y de la topografía médica disminuyeron en algo, especialmente luego de la muerte de Odriozola en 1921. Sin embargo, un buen número de doctores provincianos que trabajaban en los Andes - como parte de un incipiente sistema de salud pública - escribieron informes sobre las dimensiones topográficas y sociales de la enfermedad. Estos doctores registraban las pobres condiciones de vida de los campesinos, las chozas precarias que facilitaban la picadura del mosquito que la transmitía, y el inadecuado uso del agua para la agricultura que favorecía los reservorios de larvas. También encontraron la enfermedad en nuevos parajes de la Sierra e hicieron notar la persistencia de la creencia popular que los manantiales eran el origen de la dolencia y debían ser evitados.

Algunos de estos informes de provincias aceptaban los efectos beneficiosos de plantas medicinales usadas por la medicina tradicional y que apenas empezaban a ser descubiertas para la medicina occidental (Ortiz, 1914; Gómez, 1914). La uña de gato (Uncaria tormentosa) era considerada como una cura efectiva para la enfermedad de Carrión porque, según una creencia popular, la planta experimentaba la enfermedad. Esta convicción estaba relacionada a la persistencia de ideas neo-hipocráticas en la medicina indígena (Foster, 1994). Otro informe provinciano encontró una connotación nacionalista en el nombre popular otorgado a la enfermedad en la Sierra: «viruela de la patria» (Pérez Velásquez, 1914: 172). El término sugería que los pobladores locales estaban más familiarizados con la viruela y sufrían de leves ataques de verruga. Es importante mencionar que debido a la vacunación irregular, la viruela estaba más propagada en los Andes que en la Costa y que era una enfermedad que se considera que fue traída por los españoles. En contraste, la Enfermedad de Carrión era — probablemente junto a la sífilis - la única enfermedad infecciosa grave que se creía que existiese en América antes de la llegada de los europeos. Finalmente, según algunos expertos, existían similitudes entre las manifestaciones clínicas de la viruela y los casos de la Enfermedad de Carrión tratados en los hospitales peruanos (Kiracofe \& Marr, 2002).

Para los médicos de provincias, que no tenían recursos de laboratorio o acceso a bibliotecas modernas, las descripciones topográficas así como los estudios acerca de los tratamientos populares y las creencias sobre la enfermedad, eran formas de ganar visibilidad y reconocimiento en la capital del país. Existe una analogía entre el esfuerzo de Odriozola de publicar al extranjero, para obtener reconocimiento nacional, y el esfuerzo de estos doctores de publicar en las revistas médicas de Lima para ganar visibilidad nacional y prominencia local.

A fines de los años veinte hubo un resurgimiento del interés en la geografía médica entre los doctores peruanos y las instituciones oficiales. Un trabajo importante sobre geografía médica, que no se limitaba a la Enfermedad de Carrión, fue Estudios sobre geografía médica y patología 
del Perú de Sebastián Lorente y Raúl Flores Córdova (1925). Lorente estaba a cargo de la Dirección de Salubridad Pública, una instancia que formaba parte del Ministerio de Fomento y que había llevado a cabo un trabajo importante en la organización de un servicio nacional de salud, combatiendo epidemias en áreas rurales y urbanas. El coautor era el director del Instituto Nacional de Vacunación a cargo de la vacuna contra la viruela. Lorente usó mapas e ilustraciones para enfatizar la singularidad de la topografía médica peruana y la necesidad de usar estos conocimientos en la práctica médica. También reforzó algunas de las ideas de Odriozola como los patrones de enfermedad organizados según las tres regiones naturales y los retos médicos únicos planteados por la combinación de climas tropicales y alturas elevadas en los Andes. También acentuó la importancia de la geografía médica como una herramienta para el diseño de políticas sanitarias y advirtió que la población indígena era frecuentemente «indiferente» o estaba «en contra» de la medicina occidental (Lorente \& Flores Córdova, 1925: 11).

El interés médico, clínico y geográfico, del libro de Odriozola reapareció en Lima años después con dos publicaciones importantes. La primera fue hecha por Edmundo Escomel, un médico arequipeño, bacteriólogo entrenado en el Instituto Pasteur, y que llegó a ser Rector de la Universidad de su ciudad natal. Es importante notar que Escomel visitaba frecuentemente a Francia a la que consideraba su «segunda patria». Más aún consideraba que la influencia de Francia entre los estudiantes universitarios peruanos trascendía la medicina. En 1938 en un folleto titulado Le Pérou et la France declaró:

«declaro que eran bien conocidos el altruismo, la cordialidad y la amabilidad de los profesores franceses para enseñar la ciencia a sus alumnos». (Escomel, 1938)11

La segunda publicación de mayor impacto para las ciencias médicas peruanas fue el libro titulado Verruga Peruana (Enfermedad de Carrión) de Raúl Rebagliati (1940). El autor era un médico prominente y profesor de un curso llamado Clínica de Medicina Tropical en la Facultad de Medicina de la Universidad de San Marcos. Para ese entonces, la enfermedad había sido identificada en otros países andinos como Ecuador y Colombia así como en la vertiente oriental de los Andes (Bruce, 1995). A pesar que nuevos descubrimientos científicos habían probado que algunas de las ideas de Odriozola eran equivocadas, Rebagliati pasó por alto cualquier crítica y elogió las notables descripciones de La Maladie de Carrion. Más aún adaptó los nuevos descubrimientos científicos a estas descripciones e ignoró las ideas miasmáticas de Odriozola.

Rebagliati también recurrió a la historia de la Enfermedad de Carrión para explicar la distribución de los grupos étnicos peruanos. Para él, la decisión de los gobernantes incas de evitar construir pueblos en las secciones estrechas de los valles de los Andes, era sabia; estos sitios eran peligrosos debido a la verruga (y también a causa de otros males como la Leishmaniasis) (Rebagliati, 1940: 75). Estos pueblos andinos aparecían usualmente a 2000 metros sobre el nivel del mar y se multiplicaban a partir de esta altura, los indios también evitaban alturas extremas debido al mal de altura. Asimismo, los incas rotaban a un gran número de trabajadores y a sus familias a regiones con alturas y ecologías similares a las de las regiones de las cuales procedían. La idea que los incas tenían un sistema eficiente para manejar la población era compartida también por otros doctores como el fisiólogo de altura Carlos Monge Medrano. Para Monge Medrano y Rebagliati, mucha de esta sabiduría antigua se perdió luego de la conquista española. Ellos sugerían que los médicos de mediados del siglo veinte eran cruciales para la recuperación de este saber y el desarrollo del país (Monge Medrano, 1948).

Una diferencia importante entre el libro de Rebagliati y el de Odriozola es que Rebagliati consideraba poco fidedigna la información proporcionada por los pacientes durante la interrogación médica. Según este último, los pacientes indios confundían los lugares, lo cual hacía difícil determinar la ubicación precisa de la Enfermedad de Carrión. La «confusión»se daba debido a la «irracionalidad» de los informes proporcionados por personas que «tenía[n] una mentalidad primitiva» (Rebagliati, 1940: 165). Rebagliati confiaba más en los conocimientos 
geográficos del Perú. Su libro identificaba y describía alrededor de 600 lugares con informes positivos de la enfermedad. Esta lista fue hecha como una guía para los médicos. El aconsejaba que cualquier interrogación a un paciente que sufría de fiebre y venía de la Sierra debía ser guiada por el conocimiento de la distribución topográfica de la enfermedad de Carrión (Rebagliati, 1940: 165). Su actitud, que denotaba una mayor seguridad de la medicina occidental para determinar el mal, era congruente con un momento de mayor hegemonía y consolidación de los profesionales de salud —-sobre otros practicantes de la salud — por lo menos en las principales ciudades. En años siguientes, la idea de un patrón distinto para cada una de las tres regiones del país y la necesidad de una interrogación cuidadosa de los pacientes indígenas persistiría entre los médicos peruanos (Weiss, 1954). Como resultado de esto, las motivaciones nacionalistas, clínicas y étnicas inauguradas por Odriozola encontraron cierta continuidad.

\section{CONCLUSIONES}

El desarrollo de la medicina clínica y la geografía médica en el Perú de comienzos del siglo XX es un caso importante de recreación científica en un país marcado por desigualdades sociales, políticas y culturales. Influencias médicas francesas fueron transferidas y adaptadas a Lima durante un período de recuperación política y económica y sirvieron para contribuir a dar orden y jerarquía a distintas regiones y grupos étnicos. La emergencia de un héroe de la medicina peruana y la publicación en francés — el latín de la época- de un trabajo científico escrito por un peruano fueron la expresión que había algo interesante y único acerca de este país y que los peruanos podían contribuir al acervo médico mundial. El nacionalismo, la adaptación de la influencia europea y el prestigio de la medicina occidental se convirtieron en instrumentos para acrecentar el prestigio de una elite profesional médica que formaba parte o estaba vinculada a la aristocracia limeña de la época. Para algunos médicos de provincia, el nacionalismo médico generado en torno de la Enfermedad de Carrión y el eco de las influencias francesas, fue una oportunidad para presentar una perspectiva médico-social más amplia y para aprender acerca de la medicina popular indígena. El historiador Bolton Valencius sugiere que la geografía médica fue una forma de auto-afirmación (2000). Para los médicos peruanos de la elite y de las provincias de comienzos del siglo XX, fue esto pero también una forma de legitimar su país, de validar sus carreras y de demostrar su talento.

\section{Referencias citadas}

ALLISON, M. J., PEZZIA, A., GERSZTEN, E. \& MENDOZA, D., 1974 - A case of Carrion disease with human sacrifice from Huari culture of Southern Peru. American Journal of Anthropology, 41(2): 295-300.

ARCE, J., 1922 - Profilaxis de la verruga peruana, basada en los caracteres etiológicos y epidemiológicos propios de la enfermedad. Anales de la Facultad de Medicina, 5(1): 58-74.

BELDARRAIN, E., 2000 - La Enseñanza de la geografía médica en Cuba hasta fines del siglo XX. Revista Cubana de Educación Médica Superior, 14(2): 196-200.

BOLTON VALENCIUS, C., 2000 - Histories of Medical Geography. In: Medical Geography in Historical Perspective (Nicolas A. Rupke, eds.): 3-31; Londres: The Welcome Trust.

BRUCE, A., 1995 - A review of Bartonellosis in Ecuador and Colombia. American Journal of Tropical Medicine and Hygiene, 52(4): 354-359.

CASTRO OYANGUEREN, E., 1920 - Páginas Olvidadas, 131.

CHULTZ, M. G., 1968 - Daniel Carrion's experiment. New England Journal of Medicine, 378 (24): 1323-1326. 
La influencia francesa en la medicina peruana: Ernesto Odriozola y la Enfermedad de Carrión

LA CRÓNICA MÉDICA, 1898 - El nuevo libro del Doctor Odriozola. La Crónica Médica, 15:317322.

LA CRÓNICA MÉDICA, 1921 - Necrología Ernesto Odriozola. La Crónica Médica, 38: 98-127.

CUETO, M., 1996 - Tropical medicine and Bacteriology in Boston and Peru. Medical History, 40: 344-364.

CUETO, M., 2004 - Médecine tropicale. In: Dictionnaire de la pensée médicale (Dominique Lecourt, ed.): 1156-1161; París: Presses Universitaires de France.

DARTIGUES, L., 1927 - La Parole de L'Umfia, pour l'influence spirituelle latine dans le monde; París: Doin.

DE AREILZA, J. M., 1989 - Paris de la Belle époque, 190 p.; Barcelona: Planeta.

DELGADO MATALLANA, G., 2001 - Daniel Alcides Carrión, mártir de la medicina peruana, héroe nacional, Ley 25342, 581 p.; Lima: Universidad Nacional Mayor de San Marcos.

D'ORNELLAS, Baron, 1889 - Verrugas. In: Dictionnaire encyclopédique des sciences médicales, (A. Dechambre \& L. Lereboullet, eds.): 34-35; París: G. Mason, Tomo 3, U-Z.

DOUNON, P., 1871 - Étude sur la Verruga maladie endémique dans les Andes péruviennes; Paris, tesis.

ESCOMEL, E., 1938 - Le Pérou et la France, 100 p.; París: Impresiones Scientifiques Corbeil. Conférence faite à la Sorbonne par le Professeur Escomel. París: Biblioteca de la Academia Nacional de Medicina.

FLORES GALINDO, A. \& BURGA, M., 1980 - Apogeo y Crisis de la República Aristocrática: oligarquía, aprismo y comunismo en el Perú, 1895-1932, 235 p.; Lima: Ediciones Rikchay.

FOSTER, G. M., 1994 - Hippocrate's Latin American legacy: humoral medicine in the New World, 242 p.; Langhorne, Pa: Gordon and Breach.

FRISANCHO PINEDA, O., 1986 - El Estudiante, la verruga y la muerte, 72 p.; Lima: Editorial Los Andes.

GARCÍA-CÁCERES, U. \& GARCÍA, F.U. 1991 - Bartonellosis. An immunodepressive disease and the life of Daniel Alcides Carrión. American Journal of Clinical Pathology, 95 (4 supplement 1): S58-66.

GÓMEZ, M., 1914 - Epidemiología de la Enfermedad de Carrión o Verruga peruana en las provincias de Yauyos y Cañete. In: Actas y Trabajos, Quinto Congreso Médico Latinoamericano, Sección Tercera: Medicina Tropical: 103-138; Lima: San Martí (Sexto Panamericano, Lima, 9-16 Nov., 1913).

GUIART, J., 1925 - Verruga. In: Nouveau traité de médecine fascicule IV (Maladies infectieuses et parasitaires) (G.H. Roger et al., eds.): 402-408; París: Libraires de L'Académie de Médecine. Segunda edición revisada.

HERRER, A., 1990 - Epidemiología de la verruga, 120 p.; Lima: L. Gonzáles-Mugaburu.

HUGUET, F., 1991 - Letulle, Maurice. In: Les Professeurs de la Faculté de Médecine de Paris, Dictionnaire biographique 1794-1939: 297-299; París: Ediciones del CNRS.

KIRACOFE, J. \& MARR, J., 2002 - The Great Andean Epidemic of 1524-5: Smallpox or Bartonellosis? Manuscrito inédito.

LASTRES, J., 1957 - Daniel A. Carrión, 146 p.; Lima: Editorial San Marcos.

LORENTE, S. \& FLORES CÓRDOVA, R., 1925 - Estudios sobre Geografía Médica y Patología del Perú, 630 p.; Lima: Imprenta Americana.

LETTULE, M., 1897 - Anatomie pathologique; coeur, vaisseaux, poumons, 434 p.; París: Carré et Naud.

LETULLE, M., 1910 - Sur un Mémoire de M. Fontenoy, Directeur de l'École de Médecine de Tananarive, et Carozeau, Chef du service vétérinaire à Madagascar, concernant une affection cutanée rappelant la Verruga du Pérou, et observée à Madagascar. Extrait du Bulletin de l'Académie de Médecine (séance du 20 décembre 1910); París: L. Maretheux. Biblioteca nacional, París. 
LETULLE, M., 1955 - Notice lue à la Société Médicale des Hôpitaux de Paris, le 20 décembre 1929. In: 25 Portraits de Médecins français, 1900-1950 (Édouard Rist, ed.): 81-86; París: Masson et Cie.

MAGUIÑA, C., 1998 - Bartonellosis o enfermedad de Carrión: nuevos aspectos de una vieja enfermedad, 195 p.; Lima: A.F.A. Editores.

MAGUIÑA, C. \& GOTUZZO, E., 2000 - Bartonelossis, New and Old. Infectious Diseases of Clinical North America, 14:(1): 1-22.

MALDONADO, A., 1933 - Nuevo criterio para explicar la distribución geográfica de la Enfermedad de Carrión. La Crónica Médica, 50: 41-48.

MARC-PUSSÉGUR, F., 1898 - De la Verruga ou maladie de Carrion. Tesis de Medicina; Bordeaux.

MONGE MEDRANO, C., 1948 - Acclimatization in the Andes; historical confirmations of «climatic aggression» in the development of Andean man, 130 p.; Baltimore: Johns Hopkins University Press.

MURILLO, J. P., SALAVERRY, O., MENDOZA, W., FRANCO, G., CALDERÓN, W. \& RODRÍGUEZ, J., 2002 - Daniel Alcides Carrión y su contribución al imaginario cultural de la medicina peruana. Anales de la Facultad de Medicina, 63:2: 1-22. Acceso de internet: http://medicina.unmsm.edu.pe/of/biblioteca/anales/vol63 n2-2002/indice.htm

MATTO, D., 1908 - La Enseñanza Médica en el Perú, 66 p.; Lima: Tipografía el Lucero.

NÁQUIRA, C., 2006 - Edmundo Escomel, 1880-1959. Acta Médica Peruana, 23:3: 193-195.

ODRIOZOLA, E., 1888 - Les lésions du cœur consécutives a l'athérome des coronaires. Thèse pour le Doctorat en Médecine, s.p.; París: Imprenta A. Lanier.

ODRIOZOLA, E., 1889 - De las lesiones consecutivas al ateroma. El Monitor Médico, 5(97): 6-8.

ODRIOZOLA, E., 1898 - La Maladie de Carrion, ou la verruga péruvienne, 217 p.; París: Carré et Naud.

ODRIOZOLA, E., 1903 - Estado Actual de Nuestros Conocimientos acerca de la Enfermedad de Carrión o Verruga Peruana, 16 p.; Lima: Opinión Nacional.

ODRIOZOLA, E., 1904 - Lecciones clínicas del profesor Ernesto Odriozola, 333 p.; Lima: sin imprenta.

ODRIOZOLA, E., 1946 - La Enfermedad de Carrión o Verruga Peruana; Lima: Imprenta de la Sanidad Militar.

ORTIZ, E., 1914 - La Enfermedad de Carrión en el Departamento de Ancash. In: Actas y Trabajos, Quinto Congreso Médico Latinoamericano, Sección Tercera: Medicina Tropical: 648-666; Lima: San Martí (Sexto Panamericano, Lima, 9-16 Nov., 1913).

PARIS MÉDICAL, $1921-\mathbf{n}^{\circ} \mathbf{1 8}, 30$ abril.

PAZ SOLDÁN, J. P., 1917 - Odriozola, Ernesto. In: Diccionario Biográfico de Peruanos Contemporáneos; Lima: Lib. e Impr. Gil.

PAZ SOLDÁN, C. E., 1927 - El bronce de Carrión, 28 p.; Lima: Imp. Americana.

PEARD, J., 1999 - Race, Place, and Medicine: the idea of the tropics in nineteenth-century Brazilian medicine, 315 p.; Durham: Duke University Press.

PÉREZ VELÁSQUEZ, N., 1914 - La Verruga peruana o enfermedad de Carrión en el Departamento de Cajamarca. In: Actas y Trabajos, Quinto Congreso Médico Latinoamericano, Sección Tercera: Medicina Tropical: 157-190; Lima: San Martí (Sexto Panamericano, Lima, 9-16 Nov., 1913).

PERÚ, MINISTERIO DE HACIENDA Y COMERCIO, 1940 - Censo Nacional de Población y Ocupación, 1940, Vol I: 470-471; Lima: Imprenta Torres Aguirre.

REBAGLIATI, R., 1940 - Verruga peruana (enfermedad de Carrión), 204 p.; Lima: Imprenta Torres Aguirre.

SALAZAR BONDY, A., 1965 - Historia de las Ideas en el Perú Contemporáneo, 470 p.; Lima: Francisco Moncloa Editores. 
La influencia francesa en la medicina peruana: Ernesto Odriozola y la Enfermedad de Carrión

STIGLICH, G., 1922 - Diccionario Geográfico del Perú; Lima: Imprenta Torres Aguirre.

VALDIZÁN, H., 1911 - La Facultad de Medicina de Lima, 1811-1911, 100 p.; Lima: sin imprenta.

VALDIZÁN, H., 1919 - Ernesto Odriozola. In: Peruvians of Today ( William Belmont Parker, ed.): 216-217; Lima: Southwell press.

VALDIZÁN, H., 1920 - El Doctor Ernesto Odriozola, su vida, sus obras. Anales de la Facultad de Medicina, 4: 20: 90-150.

VALDIZÁN, H., 1922 - Elogio del Dr. Ernesto Odriozola. Anales de la Facultad de Medicina, 5(1): 31-41.

VALDIZÁN, H., 1959 - Odriozola, Ernesto. In: Diccionario de Medicina Peruana Tomo V, 2da parte: 123-124; Lima: sin imprenta.

VALLERY-RADOT, P., 1948 - Hôpital Tenon. In: Un siècle d'histoire hospitalière de Louis-Philippe jusqu'à nos jours (1837-1949): 77-80; París: Ediciones Paul Dupont.

WEISS, P., 1954 - Geografía de las Enfermedades en el Perú en relación con las zonas climáticas. Anales de la Facultad de Medicina, 37(4): 601-627.

WILLMS, J., 1997 - Paris, Capital of Europe: from the Revolution to the Belle Epoque, 436 p.; New York: Holmes \& Meier. 